\title{
Власть и традиционная культура региона в динамике журнальных репрезентаций: Тува на страницах журнала «Сибирские огни» (1920-е - 2010-е гг.)"
}

\section{Екатерина И. Красильникова}

Новосибирский государственный технический университет; Тобольская комплексная научная станция УрО РАН, Российская Федерация,

\section{Игорь А. Вальдман}

Сибирский институт управления - филиал Российской академии народного хозяйства и государственной службы при Президенте РФ, Российская Федерация
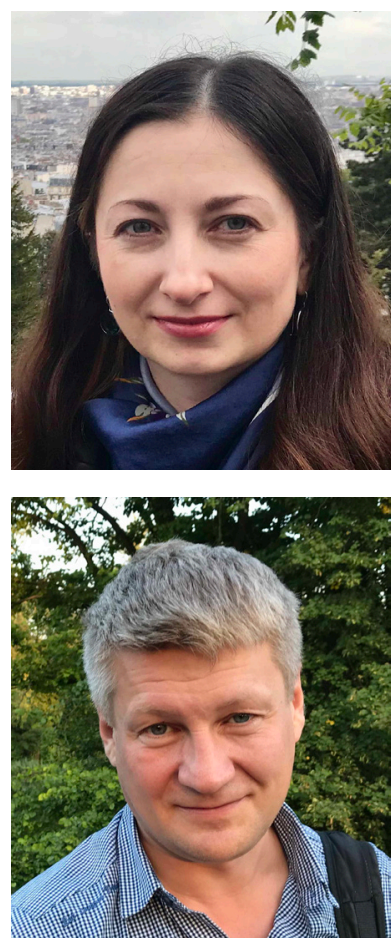

В статье раскрываются особенности репрезентаций исторического прошлого и традиционной культуры тувинского народа на страницах старейшего в Сибири и России литературно-художественного и общественно-политического журнала «Сибирские огни»с 1920-х г2. до современности в контексте динамики развития государственной политики памяти. Учитывая то, что на протяжении XX в. Тува пережила колоссальные модернизационные изменения, авторы объясняют значение коллективной памяти о прошлом для традиционного общества с точки зрения сохранения социально-политического порядка и показывают участие советского периодического издания в процессе политизации тувинской истории со стороны государственных властей.

На основе анализа журнальных публикаций на темы истории, культуры и литературы Тувы (более 30), а также делопроизводственной документации редакции «Сибирских огней» в статье прослеживается трансформация репрезентаций авторами журнала традиционной тувинской культуры. Тональность публикаций меняется от ее неприятия и критики - к попыткам увидеть в ней вновь обретенный источник самобытного развития региона. Выделяется четыре этапа процесса конструирования образов истории и традиционной культуры Тувы журналом «Сибирские огни»: с середины 1920-х до конца 1940-х г2.; с конца 1940-х г2. до начала 1980-х г2.; в 1980-е г2. и с начала 1990-х г2. до настоящего времени.

Ключевые слова: политика памяти; социальная память; традиционная культура; идеология; Тува; тувинцы; тувинская культура; «Сибирские огни»

Исследование выполнено при финансовой поддержке РФФИ и АНО ЭИСИ в рамках научного проекта № 19-011-31114.

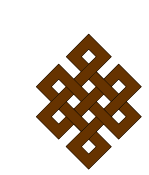

\section{Для цитирования:}

Красильникова Е. И., Вальдман И. А. Власть и традиционная культура региона в динамике журнальных репрезентаций: Тува на страницах журнала «Сибирские огни» (1920-е - 2010-е гг.) [Электронный ресурс] // Новые исследования Тувы. 2020, № 1. URL: https://nit.tuva.asia/nit/article/view/910 (дата обращения: дд.мм.гг.). DOI: 10.25178/ nit.2020.1.13

Красильникова Екатерина Ивановна - доктор исторических наук, доцент, профессор кафедры истории и политологии Новосибирского государственного технического университета; ведущий научный сотрудник Тобольской комплексной научной станции УрО РАН. Адрес: 630073, Россия, г. Новосибирск, пр. К. Маркса, д. 20. Тел.: +7 (383) 346-33-12. Эл. адрес: katrina97@ yandex.ru ORCID ID: 0000-0003-0014-0655

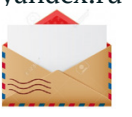

Вальдман Игорь Александрович - кандидат философских наук, доцент, доцент кафедры политических наук и технологий Сибирского института управления - филиала Российской академии народного хозяйства и государственной службы при Президенте РФ. Адрес: 630102, Россия, г. Новосибирск, ул. Нижегородская, 106. Тел.: +7(383)37312-181. Эл. адрес: veritasnostra@mail.ru ORCID ID: 0000-0002-3225-6444

Krasilnikova Ekaterina Ivanovna, Doctor of History, Associate Professor, Professor, Department of History and Political Science, Novosibirsk State Technical University; Leading Researcher, Tobolsk Complex Scientific Station of the Ural Branch of the Russian Academy of Sciences, Russian Federation. Postal address: 20, Prospekt K. Marksa, 630073, Novosibirsk, Russian Federation. Tel.: +7 (383) 346-33-12.E-mail: katrina97@yandex.ru

Valdman Igor Aleksandrovich, Candidate of Philosophy, Associate Professor, Associate Professor, Department of Political Science and Technology, The Siberian Institute of Management - branch of The Russian Presidential Academy of National Economy and Public Administration. Postal address: 6, Nizhegorodskaya St., Novosibirsk, 630102, Russian Federation. Tel.: +7 (383) 373-12-181. E-mail: veritasnostra@mail.ru 


\title{
Power and the traditional culture of a region in the dynamics of magazine representations: Tuva on the pages of the Sibirskie Ogni magazine (1920s - 2010s)*
}

\author{
Ekaterina I. Krasilnikova \\ Novosibirsk State Technical University; \\ Tobolsk Complex Scientific Station of the Ural Branch of the Russian Academy of Sciences, Russian Federation \\ Igor A. Valdman \\ Siberian Institute of Management - branch of The Russian Presidential Academy of National Economy and Public \\ Administration, Russian Federation
}

\begin{abstract}
The article examines the representations of the past and traditional culture of the Tuvan people on the pages of the "Sibirskie Ogni" ("Siberian Lights"), the oldest in Siberia (and one of the oldest surviving in Russia) literary, art and socio-political magazine. Founded in the 1920s, Sibirskie Ogni will be studied here in the context of developing a state policy of memory.

Given that during the 20th century Tuva underwent enormous modernization, the authors explain why collective memory of the past is important for traditional society in terms of maintaining socio-political order. Also shown is how the Soviet periodical helped the state authorities politicize Tuvan history.

The authors have examined over 30 publications on history, culture and literature of Tuva which appeared in the magazine, as well as editorial correspondence and documentation. The succession of these sources shows the transformation of how the magazine's authors represented traditional Tuvan culture. From harsh criticism and aversion the tone of these publications slowly changed to reveal an attempt to see it as a rediscovered source of the region's unique development model.

The article traces four stages of constructing the representations of history and traditional Tuvan culture in the Sibirskie Ogni: mid-1920s to late 1940s, late 1940s to early 1980s, the rest of the 1980s and the early 1990s to present times.
\end{abstract}

Keywords: politics of memory; social memory; traditional culture; ideology; Tuva; Tuvans; Tuvan culture; Sibirskie Ogni

" The study was sponsored by RFBR and the NPO EISI as part of a research project № 19-011-31114.

For citation:

Krasilnikova E. I. and Valdman I. A. Power and the traditional culture of a region in the dynamics of magazine representations: Tuva on the pages of the Sibirskie Ogni magazine (1920s - 2010s). The New Research of Tuva, 2020, no. 1 [online] Available at: https://nit.tuva.asia/nit/article/view/910 (access date:...). DOI: 10.25178/nit.2020.1.13

\section{Введение}

K началу XXI в. политики оценили всю значимость обладания ресурсом прошлого, то есть возможностью оказывать действенное влияние на историческую память общества. Однако политика памяти не является таким уж новым изобретением. Притом, что в советское время практики, связанные с идеологизацией прошлого, не имели специального названия, государство фактически использовало множество средств воздействия на коллективную память в целях легитимации политического режима, повышения степени доверия к государству со стороны населения, формирования и укрепления советской идентичности.

Важнейшим средством пропаганды того времени была периодическая печать. Именно из газет и журналов советские читатели узнавали о последних политических событиях, черпали идеологически окрашенные сведения об истории и природе своей огромной страны. Одним из значимых и авторитетных изданий, участвовавших в формировании и ретрансляции образов сибирских народов и их культур, стал журнал «Сибирские огни». Образы традиционной культуры и истории Тувы конструировались авторами и редакторами этого журнала под воздействием менявшейся со временем государственной идеологии. Одновременно эти образы отразили процессы трансформации сознания традиционного общества, переживавшего модернизацию, а также рефлексию внешних наблюдателей за этими процессами. Исследование комплекса публицистических и художественных текстов, посвященных истории и традиционной культуре Тувы, представляется актуальным для понимания механизмов и источников формирования исторических образов этой республики, закреплявшихся в коллективной памяти и влиявших на процессы социокультурной саморегуляции локального социума в ходе исторического развития. 
В последние десятилетия популярной стала тема сохранения и возрождения традиционных культур различных этносов. Однако тезис о том, что народы Сибири смогли до сих пор сохранить свою традиционную культуру в неизменном виде сомнителен. Нередко, «традиционное» оказывается не только и не столько воспроизведением «аутентичной истории», но некоторым новым подобием прошлого или достраиванием в виде «неотрадиционализма» (Мадюкова, Попков, 2011). В значительной степени стереотипные представления о культурных традициях автохтонных народов формировались в советское время под воздействием политизированной журналистики и художественной литературы. Именно поэтому, на наш взгляд, актуальна деконструкция подобных текстов, их «разбор» на «ингредиенты», отражающие политические противоречия в отношениях между центром и национальными районами Сибири, государственную национальную политику, культурноисторическую память сибирских этносов, специфические процессы культурной модернизации, формирования региональных, этнических и национальных идентичностей.

До сих пор история государственной политики памяти в отношении прошлого Тувы в ее содержательном и процедурном аспектах не становилась предметом самостоятельного научного исследования. Однако историками довольно глубоко изучена национальная политика СССР в ее идеологической и практической составляющих (Советская национальная политика, 2013), а также этапы формирования и реализации государственной политики в отношении народов Востока России (Луполеко, 2011). Проблемы и противоречия в подходах государства к национальной политике, а также в способах ее реализации позволяет обнаружить сопоставление взглядов «извне» и «изнутри» регионов на вопросы развития этнических культур, формирования письменности, литературного языка, распространения грамотности, становления национальной литературы, трансформации религиозности и традиционных структур социальной организации. На материалах Тувы подобные вопросы раскрываются, как в коллективных обобщающих работах по истории этой республики (История Тувы, 2016) и тувинской национальной литературы (История тувинской литературы, 2013; Самдан, 2019), так и в отдельных статьях по проблемам культурных трансформаций в XX в. (Маадыр, 2011; Отрощенко, 2015). На примере тувинского общества исследовались сложные процессы архаизации как реакции социума на происходящие социальные трансформации (Ламажаа, 2011ab). В последние годы на отдельных примерах изучаются и проблемы идеологизации посредствам журнальной прессы представлений о регионах Северо-востока России, их культурном и социально-политическом развитии в исторической динамике (Шастина, 2014).

Цель данной статьи - выявить особенности репрезентаций исторического прошлого и традиционной культуры тувинского народа на страницах старейшего в Сибири и России литературнохудожественного и общественно-политического журнала «Сибирские огни» с 1920-х гг. до современности в контексте динамики развития государственной политики памяти. Для этого предстоит решить ряд задач. Во-первых, раскрыть взаимосвязь феноменов традиции, традиционной культуры, власти и общественного сознания в социально-политической системе традиционного и развивающегося общества. Во-вторых, определить и охарактеризовать специфику этапов рефлексии истории Тувы, которые последовательно отражают публикации журнала «Сибирские огни» на хронологическом отрезке от 1920-х гг. до современности. Решая эту задачу, с одной стороны, мы остановимся на динамике смыслов политики памяти, отразившейся в репрезентациях тувинской истории на страницах интересующего нас журнального издания, с другой стороны, выявим приемы и способы работы авторов журнала с историческими образами и символами в рамках идеологизации прошлого.

Основной источник нашего исследования - журнал «Сибирские огни» - уже на протяжении целого столетия освещает в разных аспектах жизнь нашего огромного региона, неизменно уделяя внимание национальным районам и республикам. Главной темой «Сибирских огней» всегда являлась сибирская литература и литературная жизнь. Кроме художественных произведений в журнале обычно были представлены публицистические и научно-популярные статьи, посвященные истории Сибири, ее политическому и социально-экономическому развитию. Не стала исключением и Тува. Начиная со второй половины 1920-х гг. «Сибирские огни» периодически информировали своих читателей об истории, хозяйственной, культурной жизни этой республики, тогда еще не входившей в Советский Союз, о формировании тувинской национальной литературы. Публикации этого журнала отражают сочетание взгляда на сибирские народы и проблемы региона с позиции советского государства и восприятие региональных проблем самими сибирскими авторами. На содержании публикаций 
сказывался также сложный издательско-редакционный процесс согласования идеологических установок, творческих идей и находок авторов журнала. Журнальные публикации позволяют судить об этапах рефлексии его авторов трансформации традиционных основ тувинского общества, а также и о постепенном изменении позиций самих рефлексирующих субъектов. Нам удалось выявить более тридцати публикаций, тематически связанных с историей и культурой Тувы. Этот комплекс источников дополняется документами из архивного фонда «Сибирских огней», отражающих редакционную политику, а также установки журнала разных лет, обусловленные идеологией и задачами советской пропаганды.

\section{Традиция, знание о прошлом и социально-политический порядок в традиционных обществах}

Власть в территориально-политической системе самоорганизации региона (этноса) и традиционная культура находятся в противоречивых взаимоотношениях, меняющихся на различных этапах исторического развития социума, системы его социально-политической организации и общественного сознания. Общественное сознание представляет собой внутреннее опосредование в системе общественной саморегуляции. В традиционном обществе собственно традиция - унаследованный из прошлого культурно-нормативный опыт - обладает исключительной ролью в регуляции жизни общества (Вальдман, 2014: 123). Традиция является главным способом передачи социального опыта и, в основном, обуславливает поведение людей. Социум, в котором господствует традиция, практически не ориентирован на инновацию, в том числе и на познавательную деятельность для приобретения нового знания. Традиция для ее носителей обосновывается как единственная и безальтернативная интерпретация прошлого, но к реальному прошлому или к научно-историческому знанию о прошлом она практически не имеет отношения. В динамично развивающихся обществах интерес к знанию о прошлом связан с известным противоречием между «сущим» и «должным». В условиях усложнения общества даже из самого полного анализа актуальной ситуации не очевиден ответ о должном ее состоянии. То есть, историческое знание может быть использовано не только при решении вопроса об инструментальном подборе средств для заданного движения, но и для целеполагания, и для определения ценности той или иной деятельности.

При этом знание о прошлом, как в его псевдоисторической традиционной форме, так и в виде иных форм знания, в том числе и научной, нередко используются в политико-идеологических целях. Историческое знание может служить легитимации существующего социально-политического порядка и структур власти, обоснованию ответственности социальных институтов, индивидуальных и коллективных политических субъектов или снятия с них ответственности, для обвинения, или оправдания и т. д. Таким образом, культурно-историческая память, с ее специфическим отбором и формами репрезентации исторического знания становится элементом политической, правовой и моральной регуляции социума (Вальдман, 2010: 134). Культурно-историческая память в любом обществе предстает как одно из оснований социальности. А в традиционном обществе культурно-историческая память в форме традиции обладает высшей исключительностью такого нормативно-регулятивного значения, утверждаемого статусом этого знания как сакрального.

Традиционные общества меняются, несмотря на закрепленную сакральностью традиции ориентацию на неизменное повторение освященных ею прецедентов. Запуск процессов изменения нередко связан с новыми вызовами существующему устройству, появляющимися как в результате внутреннего развития, так и вследствие обновления внешних воздействий, ординарный ответ социума на которые не позволяет элиминировать их присутствие и принудительно трансформирующее влияние. В XX в. в силу исторических обстоятельств, Туве, долгое время остававшейся оазисом традиционности, приходилось также стремительно меняться. При этом, извне тувинскому обществу навязывалась «другая» история, которая, включая региональный социум в совершенно другие мировые «концептуальные рамки», девальвировала ценности традиционных исторических представлений, вытесняла на периферию культурной жизни альтернативные исторические нарративы, что вело к их забвению, грубо «прорабатывала» сюжеты традиционной устной истории, придавая им смыслы классовой борьбы и, в конечном итоге, разрушала преемственность межпоколенных социокультурных связей. Эти процессы своеобразно фиксировали «Сибирские огни». 


\section{Отражение истории Тувы в публикациях журнала «Сибирские огни»}

Тува вошла в СССР только в 1944 г. как Тувинская Автономная Область в составе РСФСР. Поэтому вплоть до начала 1940-х гг. авторы «Сибирских огней» не проявляли к Туве особенного интереса. Она воспринималась как «чужая» территория и ассоциировалась, прежде всего, с событиями гражданской войны. Прошлое Тувы специально не осмыслялось и не конструировалось. Урянхайский край лишь упоминался в негативном контексте в связи с политикой памяти, нацеленной на «проработку» недавнего военного прошлого. Первая в «Сибирских огнях» публикация о Туве принадлежала мемуаристу П. Петрову, участвовавшему в войне на стороне красных партизан ${ }^{1}$. По раннесоветскому шаблону Петров строго разделил действующих лиц своего повествования на врагов и сторонников советской власти. «Урянхаи» и «сойоты» (тувинцы), стремившиеся в это время к политической самостоятельности, получили негативные характеристики «разгулявшейся стихии», опасной силы, способной выступить на стороне врага советов. Автор представил их традиционализм как варварство: «сойоты» «разграбили библиотеку в Белоцарске и извели книги на раскурку», «разъезжали в церковных ризах, церковную утварь цепляли на себя как украшения», «обдирали и увозили железные крыши»². Во всем подчеркивалась скорее не архаичность мышления «урянхайцев», а приписываемое им бескультурье.

Сближение Тувы с Советским Союзом незадолго до Великой Отечественно войны отразила статья В. Рудмана «Тува в прошлом и настоящем» ${ }^{3}$. Она освещала 20-летнее существование Тувы в качестве независимого государства, еще сравнительно «отсталого», но вставшего на «единственно верный путь» социалистического развития вслед за Советским Союзом. Рудман использовал типичный прием политики памяти, состоявший в негативизации дореволюционного прошлого. Тува до революции 1921 г. изображалась колониальной страной, бедной, раздробленной, «обреченной на голод, нищету и вымирание». Использовался и прием обобщенной героизации целого народа, его контрастного противопоставления врагам. Тувинский народ, репрезентировался как некогда славный военной мощью, но ослабший под гнетом более многочисленных врагов: русских империалистов, китайцев и монголов, а также собственной старой знати и лам. Из рассказа следовало, что лишь помощь Советского Союза могла спасти ситуацию. Одновременно требовалось показать собственный потенциал тувинского народа к развитию, его волю и энергию. Именно поэтому Рудман рассказал о том, как в начале 1920-х гг. «простой народ» решительно закрывал ламаистские монастыри, подавлял сопротивление феодалов, добивался запретов на использование оскорбительных слов «сойоты» и «урянхаи». Традиционные культурные ценности в этой статье искажались и девальвировались: ламы и шаманы обвинялись в шарлатанстве, буддизм признавался формальной религией, черты традиционной социальной организации изображались «варварскими» («общность жен»). С отвращением перечислялись «пережитки старины»: сифилис, трахома, трупоедство, грязь в быту, высокая смертность. Культурный же выбор современности преподносится в этой статье как решительный разрыв с прошлым и модернизация: переход к оседлости, основание городов, основание добывающей промышленности, появление автотранспорта, разработка тувинского алфавита на основе кириллицы, массовое обучение чтению.

Во второй половине 1940-х гг. периодика выполняла государственный заказ на ознакомление граждан страны с основной информацией о территории, вошедшей в состав СССР. Обновленный взгляд на прошлое и современность Тувы был отражен в статье Г. Кублицкого «За голубыми Саянами» . Эта статья также акцентировала внимание на последних достижениях модернизационного развития, обусловленных помощью СССР. Однако ее автор в духе новых идеологических веяний смягчил критику традиционной культуры. К примеру, он впервые говорил о красоте двухголосого горлового пения. Сами же тувинцы, по-прежнему, репрезентировались как народ - жертва длительного паразитирования маньчжуров, местных чиновников и лам на бедняках. Однако политика памяти военного десятилетия диктовала публицистам необходимость героизировать историю народов, сражавшихся с фашизмом. Именно поэтому в тувинском прошлом был выделен и усилен эпический героический сюжет восстания семидесятилетней давности шестидесяти богатырей против китайских поработителей, за которыми, якобы, стоял весь простой тувинский народ. Восстание закончилось казнью повстанцев, что послужило

\footnotetext{
${ }^{1}$ Петров, П. (1927) Партизаны в Урянхайском крае. Воспоминания участника // Сибирские огни. № 4. С. $162-173$.

2 Там же. С. 164-165.

${ }^{3}$ Рудман, В. (1941) Тува в прошлом и настоящем // Сибирские огни. № 3. С. 114-126.

${ }^{4}$ Кублицкий, Г. (1947) За голубыми Саянами // Сибирские огни. № 5. С. 99-105.
} 
НОВЫЕ ИССЛЕДОВАНИЯ ТУВЫ

www.nit.tuva.asia

поводом подчеркнуть эффективность борьбы за свободу и процветание лишь путем революции и объединения с Советским государством. Через введение сюжета о новейшей истории письменности Г. Кублицкий зафиксировал начало процесса интенсивной русификации тувинцев с целью подготовки этого народа к восприятию советской идеологии через печатные средства пропаганды.

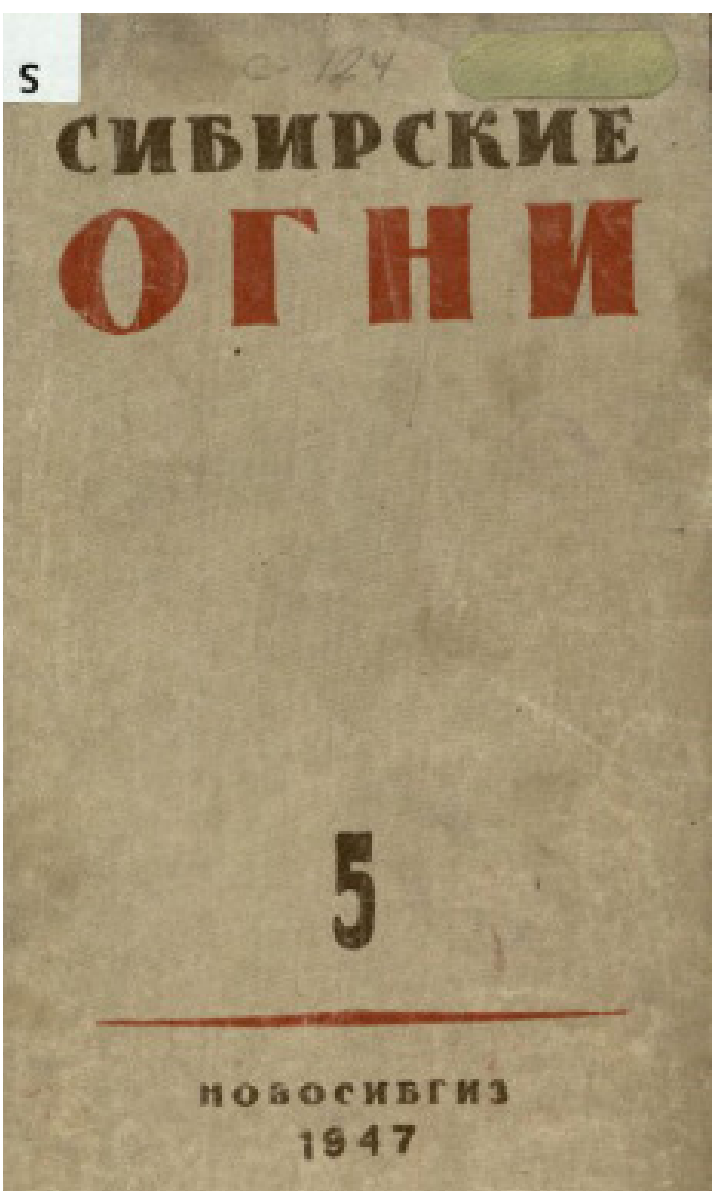

Фото 1. Обложка журнала «Сибирские огни», № 5 за 1947 г.

С 1948 г. в «Сибирских огнях» стали публиковаться литературные произведения тувинских поэтов и писателей, отражавшие их собственное участие в формировании официальных исторических образов региона. Первые литературные опыты тувинцев дополнялись литературной критикой русских авторов, судивших явно свысока, с позиции покровителей ${ }^{1}$. Критики называли тувинскую литературу самой молодой в СССР, игнорируя исторический опыт письма тувинцев на монгольском языке. Исконное народное творчество политизировано оценивалось заявлениями о том, что в старину фольклор, служащий источником сюжетов современной литературе, отражал «мысли аратов, их борьбу с насилием, злом и темными силами».

Наиболее значительные прозаические произведения тувинских писателей С.К. Токи и О.Саган-оола, публиковались в «Сибирских огнях» в 1950-1960-х гг. Эти авторы представляли первое поколение советской тувинской интеллигенции, получившей образование в Москве и вовлеченной в процессы социалистического строительства в Туве. Сегодня познакомиться с размышлениями С. К. Тока над изменениями, происходивших в тувинском обществе этих лет, можно и по его дневниковым записям, предшествовавшим написанию литературных произведений, отражающим ход мысли этого автора (см.: Ширшин, 2017). Идеологические, соцреалистические сочинения Токи и Саган-оола выражали разное отношение к истории и традиционной культуре Тувы, рефлексия которых находилась в центре авторского внимания. В 1950 г. в «Сибирских огнях» была опубликована первая часть автобиографического романа С. К. Токи «Слово арата» под заглавием «К большому порогу»². В этом произведении, удостоенном престижной Государственной премии и переведенном на несколько языков, нет и намека на сколько-нибудь позитивное восприятие традиционной культуры и общественного уклада дореволюционного тувинского общества. Тувинская старина репрезентируется через образы крайней нищеты и социальной несправедливости. По сюжету произведения такая беспросветная жизнь определила политический выбор героя и его решение любой ценой вырваться из этой обстановки самому и возглавить общественную борьбу за перемены.

Однако радикальное неприятие тувинского прошлого разделяли не все писатели республики, о чем с досадой заявляли в начале 1950-х гг. литературные критики «Сибирских огней». Так, уже достаточно авторитетный тувинский писатель О. Саган-оол обвинил своих коллег в фактическом «бездушном любовании» национальной стариной, «патриархально-кочевой жизнью», в ее поэтизации, в «неумении по-марксистски правильно обобщать прошлое» ${ }^{3}$ В «Сибирских огнях» такие произведения не публиковали. А критики напоминали писателям, что советская власть ставит перед тувинскими авторами большие задачи идейного воспитания народа и упрекали их в отставании развития тувинской литературы от экономики.

${ }^{1}$ Шмаков, А. (1948) Молодая литература советской Тувы // Сибирские огни. № 2. С. 98-101.

${ }^{2}$ Тока, С. К. (1950) К большому порогу // Сибирские огни. № 2. С. 5-77.

${ }^{3}$ Саган-оол, О. (1952) Советская тувинская литература // Сибирские огни. № 6. С. 174-175. 
Между тем, уже в 1965 г., на фоне хрущевской оттепели С. А. Сарыг-оол опубликовал в «Сибирских огнях» собственную автобиографическую «Повесть о светловолосом мальчике» ${ }^{1}$, явно ностальгического характера, полную тонких этнографических описаний повседневного быта кочевников, семейных, общественных отношений, верований и обычаев народа, мало знакомого с европейской цивилизацией. Документальность создавала иллюзию аутентичности, неизменности и подлинности описанных традиций. Однако показную документальность стоит расценивать как ловушку политики памяти, призванную усыплять критическое восприятие репрезентаций истории. Картину прошлого Сарыгоол конструировал по строгим канонам соцреализма и в соответствии с государственной политикой памяти, направленной на формирование новой идентичности тувинцев, которая должна была включать, как национальный (отсюда и ностальгия), так и общесоветский компоненты.

Одновременно, в 1950-1960-х гг. «Сибирские огни» отражали интерес к Туве извне, со стороны русских ученых: археологов, этнографов, фольклористов и историков. Это был новый этап формирования в общественном сознании образов различных регионов советской страны, в основе которых должны были лежать уже не просто обусловленные идеологически голословные заявления об их прошлом, как о мрачном и беспросветном, но и данные науки, уточняющие и усложняющие эти заявления, как впрочем, и художественная литература. Главный месседж научно-популярных публикаций 1960-х гг. сводился к тезису о том, что, хотя тувинское общество трансформируется, традиционная культура в Туве еще во многом сохранилась, а это делает республику интересной для ученых, наравне с другими советскими республикамиㄹ․

В 1950-1960-х гг. в Туве активно работали фольклористы, собиравшие и публиковавшие народные сказки. Их сборники выходили, по сведениям «Сибирских огней», в 1954, 1958 и 1964 г. в Кызылез За устным народным творчеством признавался большой воспитательный потенциал. В целом же, при всем внимании к традициям словесности и фольклора народов Сибири и признании за фольклором значения «хранилища вековой мудрости», в советское время считалось, что писателям и поэтам необходимо преодолевать сохранение и воспроизведение фольклорных традиций в чистом виде, используя их в профессиональном литературном творчестве только в качестве «строительного материала». Самостоятельная же ценность фольклорных традиций отрицалась.

В конце 1960-х гг. тувинская литература постепенно переориентировалась с исторических тем на темы современности ${ }^{4}$. Республика сильно менялась в связи с существенным промышленным ростом. Это вело к трансформациям и в образе жизни, и в мировоззрении тувинцев. В республике ощущался разрыв с историческим прошлым, вызванный процессами экономической модернизации. В 1970-х гг. в идеологические задачи «Сибирских огней» входили освещение успехов хозяйственного развития в Сибири, связанного с реализацией планов XX пятилетки, а также демонстрация успехов развития национальных литератур, что понималось как значимый результат социалистического строительства (Государственный архив Новосибирской области - далее ГАНО. Ф. Р-1467. Оп. 1. Д. 1378, л. 5; 15-16). В этой связи прошлое Тувы, как и других национальных районов Сибири, перестало восприниматься как актуальная тема. Похожие одна на другую национальные литературы всецело концентрировали внимание на проблемах современности.

Однако социалистические стройки оборачивались проблемами: они вредили экологии и культурному наследию, на что стали обращать внимание краеведы и ученые. В частности, академик А. П. Окладников выступил с призывом к общественности обратить внимание на угрозу утраты древних тувинских петроглифов Улуг-Хема из-за грядущего затопления «водами нового искусственного моря», которое образуется после строительства Саяно-Шушенской ГЭС.

В последующие десять лет «Сибирские огни» не обращались к теме тувинской литературы, которая, по словам одного из авторов журнала, в 1970-х гг. пребывала в состоянии «напряженного поиска». Редакция «Сибирских огней» сетовала и на недостаток кадров переводчиков с тувинского языка, способных работать с крупными прозаическими произведениями (ГАНО. Ф.Р-1467. Оп. 1. Д. 1378, л. 16). Лишь в 1981 г. была опубликована статья 3. Самдана о новом крупном романе тувинского автора

\footnotetext{
${ }^{1}$ Сарыг-оол, С. А. (1965) Повесть о светловолосом мальчике // Сибирские огни. № 10. С. $3-77$.

${ }^{2}$ Потапов, Л. (1962) Новое в истории народностей Тувы // Сибирские огни. №7. С. 150-154.

${ }^{3}$ Изынеева, М. (1965) Сказки Тувы // Сибирские огни. № 9. С. 185.

${ }^{4}$ Хадаханэ, М. А. (1967) Весна тувинской литературы // Сибирские огни. № 7. С. 182-183.

${ }^{5}$ Окладников, А. П. (1977) М. А. Дэвлет. Петроглифы Улуг-Хема // Сибирские огни. № 11. С. 190-191.
} 
НОВЫЕ ИССЛЕДОВАНИЯ ТУВЫ

www.nit.tuva.asia

К. Кудажы «Улуг-Хем неугомонный» ${ }^{1}$. Это, еще неоконченное произведение, было названо «эпосом нового времени, в котором обобщен образ тувинского народа» и признано величайшим литературным достижением Тувы.

В ознаменовании 40-летия Тувинской АССР, в 1984 г. «Сибирские огни» опубликовали статью первого секретаря Тувинского обкома КПСС Г. Ширшина «Республика в Саянах» ${ }^{2}$. В этой работе упрощенно воспроизводился уже сложившийся исторический нарратив, отражающий идею разрыва тувинского народа с мрачным прошлым, из чего ценными признавались лишь внешние формы традиционной культуры, которые только в советское время наполнились «подлинным» социалистическим содержанием. Стихи тувинских авторов, опубликованные к юбилею республики, как и проза, претендовали на обобщение опыта и судьбы целого народа через эпические картины прошлого, уже закреплённые в культурной памяти тувинцев ${ }^{3}$. Прошлое репрезентировалось как урок, который должен быть усвоен в настоящем для решения общечеловеческих задач. Поэзия реабилитировала национальное прошлое в контексте воспитания патриотизма и любви к Родине, как к малой Родине, как к отчему дому, где царит мир.

1990-е гг. были чрезвычайно трудными для «Сибирских огней», как и для отечественной журналистики в целом. Это десятилетие ничего не добавило к журнальным репрезентациям жизни в Тувинской республике и ее истории. Однако уже в XXI в. «Сибирские огни» вновь обратились к тувинской теме. На этом этапе деконструкции и «разоблачению» подвергся уже опыт представления традиции советского времени.

Из новейших публикаций, имеющих отношение к теме данного исследования, особенно интересно обратить внимание на интервью с филологом М. А. Хадаханэ, которая еще во второй половине 1960-х гг. публиковала в «Сибирских огнях» свои статьи, посвященные тувинской литературе. Бурятка по происхождению М. А. Хадаханэ рассказала о том, что в 1945 г. она переехала жить в Туву, а с 1955 г. начала изучать тувинский фольклор. В своем интервью она раскрыла ту сторону исследований тувинского фольклора, которая не могла быть показана советским журналом в 1950-1960-х гг. Так, желая узнать больше о традиционной культуре тувинцев, Хадаханэ обращалась с вопросами к ламам и сказителям, которые, имея негативный опыт взаимодействия с советскими учеными и представителями администрации, не сразу шли на контакт, отговаривались от расспросов тем, что, якобы, ничего не помнят. Такое отношение к расспросам со стороны молодого поколения являлось очевидным результатом

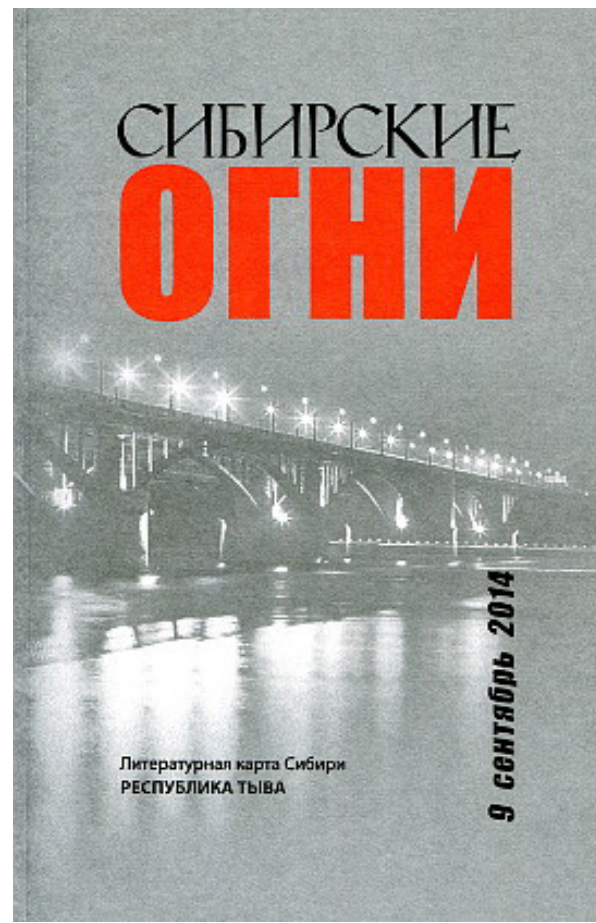

Фото 2. Обложка журнала «Сибирские огни», № 9 за 2014 г. реализации советской культурной политики и политики памяти и в будущем стало фактором разрыва традиции. Только лишь тайная демонстрация познаний в области буддизма давала возможность Хадаханэ расположить к себе лам, которые соглашались даже показать пещеры, где хранились сутры. Получив ценные сведения от лам, Хадаханэ, как и другие ученые, не могла писать и публиковать работы, которые могли бы способствовать сохранению культурной преемственности между поколениями ${ }^{4}$.

Трендом XXI в. стало открытое переосмысление самими тувинцами их национальной культуры. По словам автора еще одной статьи из «Сибирских огней», И. Качан, Тува переживает культурный ренессанс ${ }^{5}$. Это объясняется, прежде всего, инициативами К.Б. Ондара - знаменитого тувинского певца,

\footnotetext{
${ }^{1}$ Самдан, 3. (1981) Освоение эпоса // Сибирские огни. № 9. С. 166-169.

${ }^{2}$ Ширшин, Г. (1984) Республика в Саянах // Сибирские огни. № 10. С. 117-122.

${ }^{3}$ Кюнзегеш, Ю. (1984) Наскальные рисунки // Сибирские огни. № 10. С. 12-13.

${ }^{4}$ Донгак, А. (2014) Тува - судьба моя [Электронный ресурс] // Сибирские огни. № 9. URL: http://www.sibogni. ru/content/tuva-sudba-moуa (дата обращения: 10.11.2019). С 2000 года журнал стал издаваться в электронном виде. Сайт журнала: http://www.сибирскиеогни.рф/

${ }^{5}$ Качан, И. (2014) Центр Азии. Заметки о Туве [Электронный ресурс] // Сибирские огни. № 9. URL: http://www. sibogni.ru/content/centr-azii (дата обращения: 10.11.2019).
} 
мастера горлового пения, ставшего депутатом Верховного Хурала Тывы и во многом определившего культурную политику в республике, поддерживаемую тремя последними российскими президентами. По словам И. Качан, Конгар-оол Ондар «создал современную Туву, Туву, которую мы уже привыкли видеть» ${ }^{1}$. Автор этой статьи фактически использует классический прием политики памяти, нацеленный на девальвацию ценностей предшествующего исторического этапа (на этот раз, уже советского) для утверждения верности выбора пути дальнейшего развития в современности. И. Качан описывает позднесоветскую Туву, утратившую этнический колорит: «Да, строились комбинаты, поднималась индустрия, колхозы выдавали всю положенную продукцию. Республика развивалась, как, впрочем, и другие окраины страны. А Тувы - не было! Не было ярких национальных костюмов на улицах, горловики были, хоть и мало, концерты - редки...»; «Да, под руководством партии вместе со всеми шли в светлое будущее. Забывая о ярком прошлом. Всерьез начинали думать, что все национальное, самобытное, свое - это пережитки темного прошлого»². Описывается интерес Конгар-оола к тувинской традиции, вызванный, помимо прочего, увиденным им подчеркнутым вниманием к своим традициям в странах Запада. В результате его деятельности в моду вошли как аутентичные, так и стилизованные элементы традиционной культуры: публичное проведение ламаистских и шаманских обрядов, ношение традиционализированной одежды и причесок, исполнение традиционной и стилизованной музыки. Автор статьи называет это «культурным ренессансом» Тувы, куда включается не только возрождение ранее лишь известного по написанному в книгах, но и осознанное постоянное придумывание нового в традиционном ключе.

\section{Заключение}

Итак, на протяжении почти целого столетия журнал «Сибирские огни» конструировал образы истории и традиционной культуры Тувы, что происходило под воздействием менявшейся с течением времени политики памяти. Журнал отразил на своих страницах изменение использования культурноисторической памяти и ее специфических форм репрезентации исторического знания в рамках символической, прежде всего, политико-идеологической саморегуляции тувинского общества в меняющихся общероссийских контекстах и перспективах.

В этом процессе можно выделить следующие основные этапы.

На первом этапе, с середины 1920-х до конца 1940-х гг. о Туве в «Сибирских огнях» публиковались лишь работы русских публицистов, отражавшие шаблонный, негативно-обобщенный взгляд на историю республики извне, из страны Советов.

На втором этапе с конца 1940-х гг. до начала 1980-х гг. в «Сибирских огнях» стали появляться работы тувинских авторов (писателей и поэтов), осваивавших русскую культуру и становившихся на службу советской идеологии. Они воспроизводили негативное отношение к тувинскому прошлому, которому противопоставлялись успехи советской модернизации. Произведения художественной литературы тувинских писателей, богатые бытовыми и этнографическими деталями, использовались журналом для подтверждения идеологических формул. Хотя в литературных произведениях 1960-х гг. сквозила ностальгия, культурная модернизация и пропаганда сделали свое дело. В условиях вынужденного молчания еще живых носителей традиционной культуры и, обусловленного советской культурной политикой и политикой памяти, отсутствия в обществе запроса на традицию, образовался поколенческий разрыв в воспроизводстве культурных традиций новыми поколениями, который отразили, в частности, «Сибирские огни». О Туве одновременно писали русские ученые и литературные критики, выражавшие официальный взгляд на республику извне: происходила частичная реабилитация элементов традиционной тувинской культуры в части ее элементов, не противоречивших прогрессистски-цивилизаторским декларациям советской идеологии. Критикам «Сибирских огней» вторили и авторы из Тувы - публицисты, обозреватели, как, к примеру, бурятка М. А. Хадаханэ.

На третьем этапе (с 1980-х гг. - до начала 1990-х гг.) фактически угасла живая социальная память старшего поколения, еще помнившего дореволюционное прошлое Тувы, были забыты повседневные практики традиционной культуры. В этих условиях началась искусственная теоретизация культурной памяти этноса с уклоном в экологизм. Традиционная культура и история Тувы при этом все больше

\footnotetext{
1 Там же.

2 Там же.
} 
становились интересными ученым в русле научного поиска и музеефикации этнокультурного наследия. $\mathrm{B}$ «Сибирских огнях» печаталась не только поэзия и проза, но также и публицистика тувинских авторов (Г. Ч. Ширшин), включенных в общественно-политическую жизнь республики. Однако эти авторы продолжали писать о прошлом Тувы в русле советских идеологических интерпретаций общественного развития.

На четвертом, постсоветском этапе (с 1990-х гг. - до настоящего времени) фактически рухнул советский модернизационный проект. В силу экономических обстоятельств регион утратил многие существенные возможности коммуникации с общекультурным целым страны, и фактически состоялась «приватизация» этнократическими элитами власти в своих регионах. Новым элитам требовалась легитимация их прав на экономическую и политическую власть. Именно на этом фоне актуализировался выраженный интерес к «исконным традициям», уже практически утраченным. В середине 2010-х гг. «Сибирские огни» отразили тенденцию так называемого «архаического взрыва», связанную с временной утратой иных сложных механизмов самоорганизации локального социума. Поскольку «исконной традиции» фактически уже не существует, ее изобретают и конструируют на основе книжных знаний, комплекс которых в значительной степени сформировался в советское время. В спецвыпуске журнала, посвященном Туве (2014, № 9), были опубликованы исключительно работы авторов из Тувы: писателей и поэтов - преимущественно этнических тувинцев и публицистов не тувинского происхождения, живущих в республике ${ }^{1}$. Спецвыпуск показывает, что на новом этапе «Сибирские огни» стали представлять не внешний взгляд на Туву, а предоставлять авторам возможность саморепрезентации тувинской культуры, которая отразила, в немалой степени, текущие процессы архаизации.

\section{СПИСОК ЛИТЕРАТУРЫ}

Вальдман, И. А. (2010) Социокультурная рефлексия свободы: политогенез и культурно-историческая память // Высшее образование в России. № 12. С. 131-136.

Вальдман, И. А. (2014) Традиционное общественное сознание и социальная коммуникация // Идеи и идеалы. № 4 (22). Т. 1. С. 123-129.

История тувинской литературы (2013) / отв. ред. К. А. Бичелдей. Новосибирск : Наука. 264 с.

История Тувы (2016) : в 3 т. / под общ. ред. Н. М. Моллерова. Новосибирск : Наука. Т. 3. 451 с.

Ламажаа, Ч. К. (2011a) Архаизация общества в период социальных трансформаций // Знание. Понимание. Умение. № 3. С. 35-42.

Ламажаа, Ч. К. (2011b) Тува между прошлым и будущим. 2-е изд. СПб.: Алетейя. 368 с.

Луполеко, Н. А. (2011) Основные черты государственной политики в отношении малочисленных народов севера России в 1936-1957 гг. // История государства и права. № 4. С. 27-36.

Маадыр, М. С. (2011) Книжная культура Тувинской Народной Республики: позитивные и негативные тенденции [Электронный ресурс] // Новые исследования Тувы. № 2-3. URL: https://nit.tuva.asia/nit/ article/view/406 (дата обращения: 10.11.2019).

Мадюкова, С. А., Попков, Ю. В. (2011) Феномен социокультурного неотрадиционализма. СПб.: Алетейя. 132 с.

Отрощенко, И. В. (2015) Языковая политика и культурное строительство в Тувинской Народной Республике [Электронный ресурс] // Новые исследования Тувы. №. 2. URL: https://nit.tuva.asia/nit/ article/view/22 (дата обращения: 10.11.2019).

Самдан, 3. Б. (2019) Модификация архетипического образа тувинского шамана в творчестве М. Б. Кенин-Лопсана [Электронный ресурс] // Новые исследования Тувы. № 3. URL: https:/nit.tuva.asia/ nit/article/view/872 (дата обращения: 20.11.2019). DOI: 10.25178/nit.2019.3.13

Советская национальная политика: идеология и практики, 1945-1953 (2013) / сост. Л. П. Кошелева, О. В. Хлевнюк (отв. сост.) [и др.] М. : РОССПЭН. 949 с.

Шастина, Т. П. (2014) Ойротия на страницах журнала «Сибирские огни»: начальный этап формирования образа советской национальной окраины // Вестник ТГУ. Филология. № 4. С. $158-172$.

${ }^{1}$ Литературная карта Сибири. Республика Тыва: спецвыпуск (2014). Сибирские огни. № 9. URL: http://www. sibogni.ru/content/centr-azii (дата обращения: 10.11.2019). 
Ширшин, Г. Ч. (2017) Летопись советской Тувы 1950-1960-х гг. в дневниках Салчака Тока [Электронный ресурс] // Новые исследования Тувы. № 4. URL: https://nit.tuva.asia/nit/article/view/739 (дата обращения: 20.11.2019). DOI: 10.25178/nit.2017.4.4

\section{REFERENCES}

Valdman, I. A. (2010) Sotsiokul'turnaia refleksiia svobody: politogenez i kul'turno-istoricheskaia pamiat' [Sociocultural reflection of freedom: the genesis of politics, cultural and historical memory]. High Education in Russia, no. 12. pp.131-136. (In Russ.).

Valdman, I. A. (2014) Traditsionnoe obshchestvennoe soznanie i sotsial'naia kommunikatsiia [Traditional public consciousness and social communication]. Ideas and Ideals, no. 4 (22), vol. 1, pp. 123-129. (In Russ.).

Istoriia tuvinskoi literatury [A History of Tuvan Literature] (2013). Novosibirsk, Nauka. 264 p. (In Russ.).

Istoriia Tuvy [The History of Tuva] (2016): in 3 vols. / ed. by V. A. Lamin. Novosibirsk, Nauka. Vol. 3. 455 p. (In Russ.).

Lamazhaa, Ch. K. (2011a) Arkhaizatsiia obshchestva v period sotsial'nykh transformatsii [The Archaization of Society in the Period of Social Transformations]. Znanie. Ponimanie. Umenie, no. 3, pp. 35-42. (In Russ.).

Lamazhaa, Ch. K. (2011a) Tuva mezhdu proshlym i budushchim [Tuva between the past and the future]. 2nd ed. St. Petersburg, Aleteiia. 368 p. (In Russ.).

Lupoleko, N. A. (2011) Osnovnye cherty gosudarstvennoi politiki v otnoshenii malochislennykh narodov severa Rossii v 1936-1957 gg. [The basics of state on indigenous peoples of the North of Russia in 1936-1957]. History of state and law, no. 4, pp. 27-36. (In Russ.).

Maadyr, M. S. (2011) Knizhnaia kul'tura Tuvinskoi narodnoi respubliki: pozitivnye i negativnye tendentsii [Book culture of the Peoples' Republic of Tuva: positive and negative tendencies]. The New Research of Tuva, no. 2-3 [online] Available at: https://nit.tuva.asia/nit/article/view/406 (access date: 10.11.2019). (In Russ.).

Madiukova, S. A. and Popkov, Yu. V. (2011) Fenomen sotsiokul'turnogo neotraditsionalizma [The phenomenon of socio-cultural neotraditionalism]. St. Petersburg, Aleteiia. 132 p. (In Russ.).

Otroshchenko, I. V. (2015) Iazykovaia politika i kul'turnoe stroitel'stvo v Tuvinskoi Narodnoi Respublike [The language policy and cultural building in the Tuvan People's Republic]. The New Research of Tuva, no. 2. [online] Available at: https://nit.tuva.asia/nit/article/view/22 (access date: 10.11.2019). (In Russ.).

Samdan, Z. B. (2019) Modifications of the archetypal image of the Tuvan shaman in the works of M. B. Kenin-Lopsan. The New Research of Tuva, no. 2 [online] Available at: https://nit.tuva.asia/nit/article/view/872 (access date 20.11.2019). DOI: 10.25178/nit.2019.3.13

Sovetskaia natsional'naia politika: ideologiia i praktiki, 1945-1953 (2013) [Soviet National Politics: Ideology and Practices, 1945-1953] / Eds. by L. P. Kosheleva and O. V. Hlevniuk. Moscow, ROSSPEN. 949 p. (In Russ.).

Shastina, T. P. (2014) Oirotiia na stranitsah zhurnala «Sibirskie ogni»: nachal'nyi etap formirovaniia obraza sovetskoi natsional'noi okrainy [Oirotia on the pages of the Sibirskiye Ogni magazine: the initial stage in the representation of the Soviet ethnic peripheries]. Tomsk State University Journal, Philology series, no. 4. pp. 158-172. (In Russ.).

Shirshin, G. Ch. (2017) A Chronicle of the Soviet Tuva (1950s-1960s) in the Diaries of Salchak Toka. The New Research of Tuva, no. 4 [online] Available at: https://nit.tuva.asia/nit/article/view/739 (access date: 20.11.2019). DOI: $10.25178 /$ nit.2017.4.4 